\title{
Complications during removal of a pedunculated endobronchial leiomyosarcoma
}

\author{
AL. ANNAMALAI, S. SHREEKUMAR, P. VADIVELU, \\ and P. SH YA M A L A \\ Department of Medicine, Madras Medical College, and General Hospital, Madras, India
}

Pedunculated endobronchial leiomyoma or leiomyosarcoma is comparatively rare and is known to produce intermittent, partial or complete obstruction of the ipsilateral lung. Rarely it causes obstruction of the contralateral main bronchus. Fatalities have been caused by obstruction of the contralateral main bronchus during surgery. A pedunculated intrabronchial leiomyosarcoma obstructing the contralateral main bronchus is reported.

Some 29 cases of primary leiomyosarcoma of the lung have been reported (Gale and Delarue, 1967). Arising from smooth muscle in the bronchi or blood vessels, leiomyoma is a rare tumour and stands fourth in the frequency of primary mesodermal tumours of the lung, being preceded by fibroma, chondroma, and lipoma (Andrews, 1965). Detachment of the tumour during operation has resulted in contralateral obstruction and death in cases of leiomyosarcoma (Brunn and Goldman, 1940).

\section{CASE REPORT}

A 21-year-old college girl with no significant previous illness was admitted to hospital for investigation of recurrent attacks of dyspnoea, cough, chest pain, and

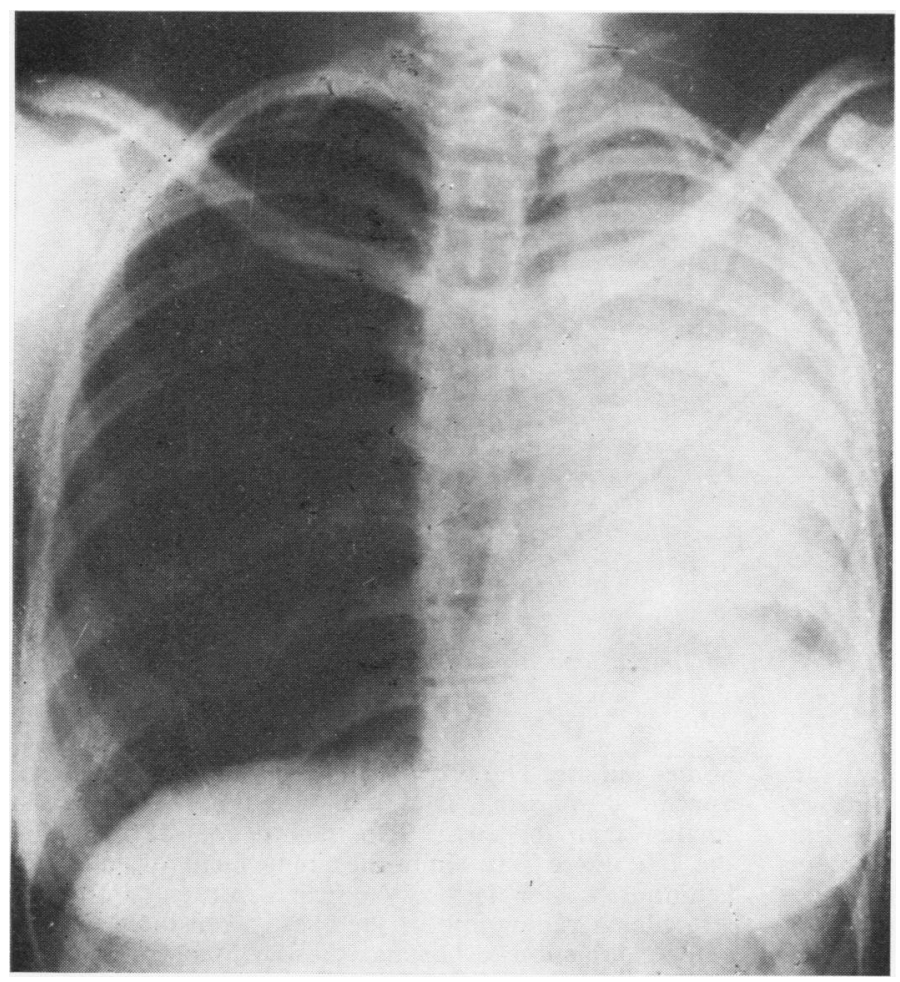

FIG. 1. (a) Total atelectasis of left lung. 


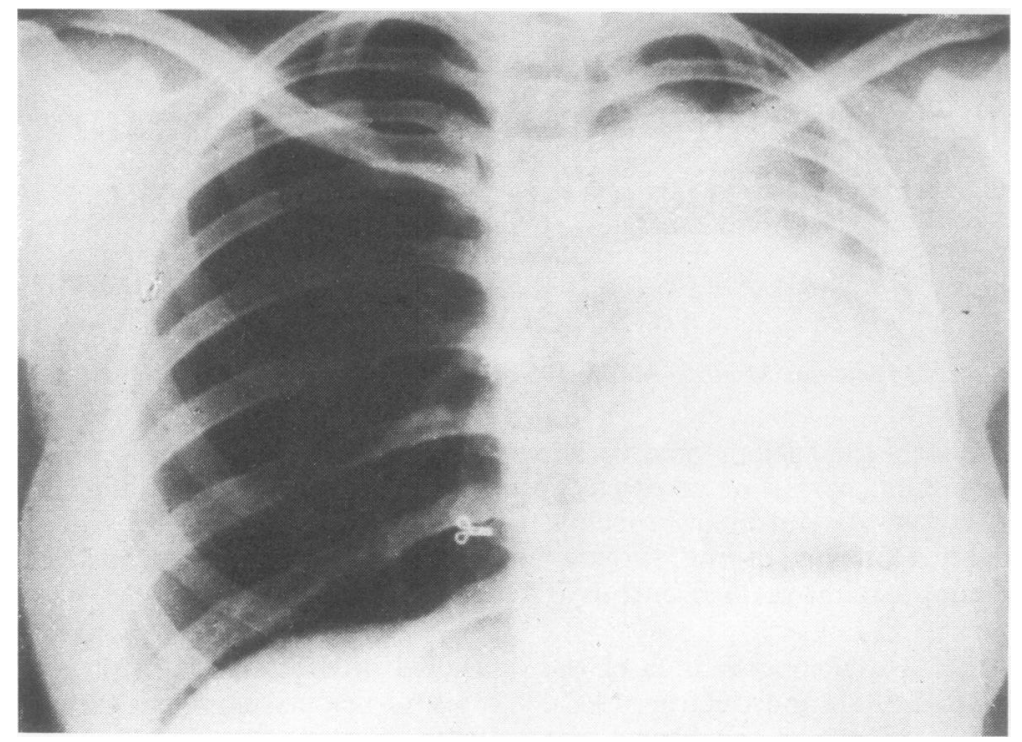

FIG. 1. (b) Partial re-aeration of left lung.

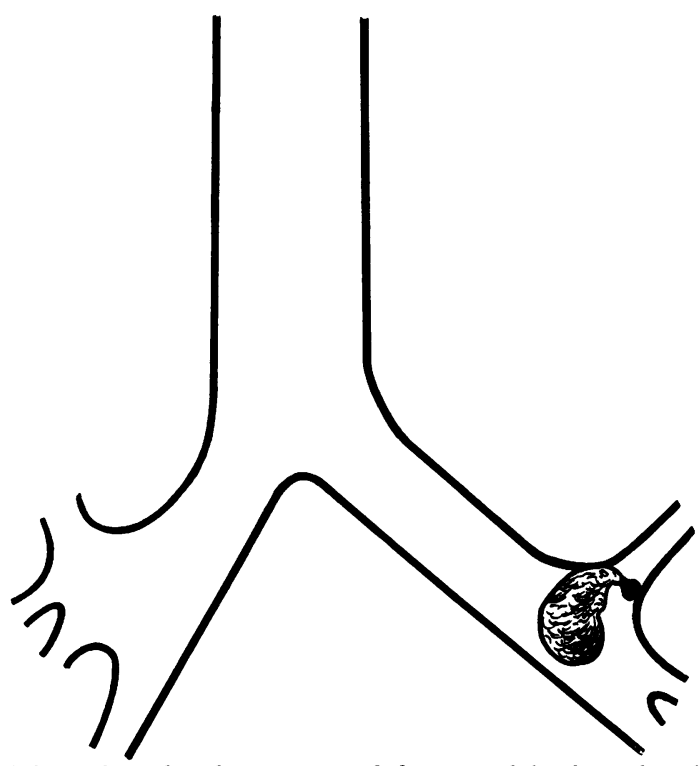

FIG. 2. Mobile pedunculated tumour in left upper lobe bronchus blocking left upper and lower lobe bronchus.

fever. These symptoms had begun suddenly four months before admission while she was travelling by car and had been alleviated with parenteral medication. Since then she had had a recurrence of symptoms on three occasions which had responded to antibiotics and bed rest. On admission she was afebrile. The blood pressure was $110 / 70 \mathrm{mmHg}$ and the pulse was
86 per minute. There was no cyanosis and she did not appear dyspnoeic. The left hemithorax appeared smaller than the right. The trachea was deviated to the left, there was diminished movement of the left hemithorax, and markedly impaired air entry on the left side. A radiograph of the chest taken three weeks before admission to hospital showed total collapse of 


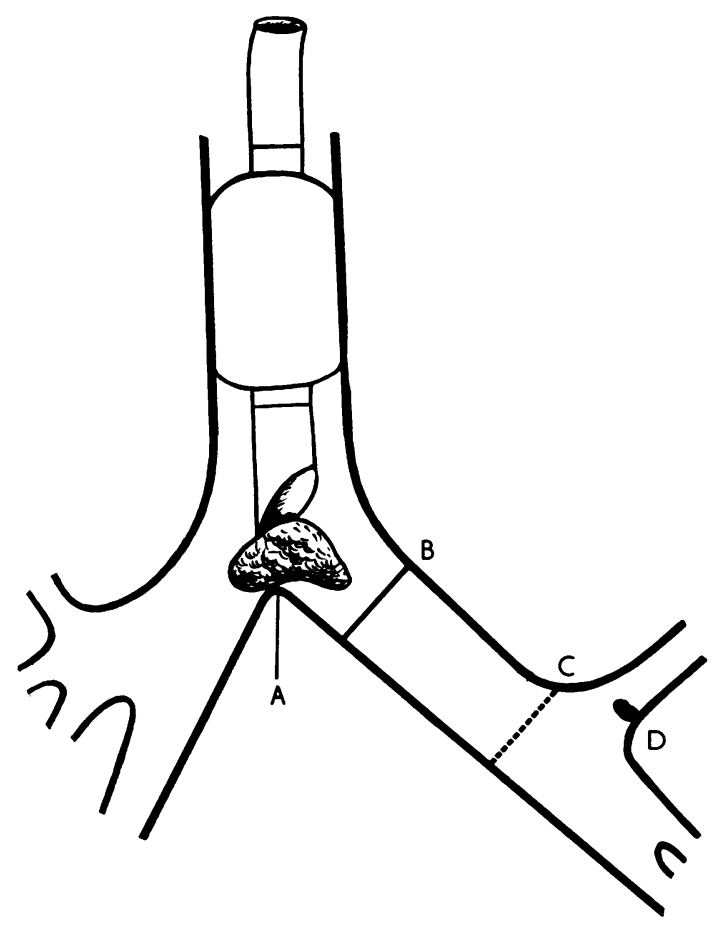

FIG. 3. (A) Spontaneously detached tumour blocking air flow through endotracheal tube and right main bronchus; (B) left bronchial closure; $(C)$ bronchotomy site; $(D)$ site of tumour.

the left lung (Fig. 1a) while Fig. 1b, taken the day before admission, showed some re-aeration. Bronchoscopy revealed a tumour in the left upper lobe bronchus.

At thoracotomy two weeks later the left lung was found to be totally atelectatic. Neither suction nor positive pressure effected expansion of the lung. The tumour was felt in the upper lobe bronchus just distal to its origin (Fig. 2). Hilar glands did not appear to be involved, the pleura was not thickened, and there were no adhesions. It was decided to proceed with pneumonectomy. As the left main bronchus and bronchial vessels were being isolated the anaesthetist was alarmed to find obstruction to air entry and poor return from the right lung. Positive pressure, suction, and manipulation were all ineffective. As the heart was slowing and a catastrophe appeared imminent, the left main bronchus was opened $4 \mathrm{~cm}$ from the carina and the tumour was found to have become detached and lodged near the carina where it was blocking the right main bronchus (Fig. 3). Positive pressure through the endotracheal tube resulted in the tumour escaping through the bronchotomy and immediate improvement in respiration and cardiac function.

Dissection of the lung after pneumonectomy revealed the tumour to be a pedunculated growth,
$5 \mathrm{~cm}$ by $1 \mathrm{~cm}$, arising from the submucosal layer of the bronchus. Histopathological examination revealed appearances consistent with leiomyosarcoma. Postoperative recovery was uneventful.

\section{DISCUSSION}

Leiomyoma may be single or multiple, involving one or more systems; the skin may be involved and malignant changes may be present in portions of the tumour (Castleman, 1963). Leiomyoma may arise primarily in the bronchus or lung. Pedunculated endobronchial tumours are comparatively rare. Agnos and Starkey (1958), reviewing 14 cases of leiomyoma, found one pedunculated tumour which blocked the right upper lobe bronchus producing atelectasis (Freireich, Bloomberg, and Langs, 1951). Among 18 cases of leiomyosarcoma reviewed by the same authors a portion of a tumour in one patient became dislodged and blocked the contralateral bronchus. Of the cases reported in the literature the age has varied from 4 to 72 years (Gale and Delarue, 1967), and no definite predilection for either sex has been found. Some are asymptomatic and discovered at necropsy. When symptoms are present, cough, dyspnoea, and chest pain are common, whereas haemoptysis, fever, weight loss, and weakness are less frequent (Shaw, Paulson, Kee, and Lovett, 1961). Situated within the bronchus the tumour may cause partial, intermittent or complete obstruction, depending upon the degree of occlusion of the bronchus and ball valve action. Bronchoscopy can reveal only accessible growths. Parenchymal and peripheral lesions may be seen as a mass in a plain chest film or may show distortion of the bronchial tree in bronchographic studies. Endoscopic biopsy may reveal the true histological nature of the tumour. Depending upon the anatomical location and complications, endobronchial or segmental resection, lobectomy or pneumonectomy may be necessary. Removal of a foreign body from the bronchus is fraught with the danger that it may slip and obstruct the contralateral bronchus. Similar obstruction during removal of intrabronchial growths, though rare, may end fatally. Deaths reported might have been caused by cardiac standstill due to vagal irritation at the carina or by anoxia due to bronchial blocking. This emergency may be anticipated and prevented by endobronchial intubation using a White tube for the right side and a Carlen tube for the left side.

Our thanks are due to the Dean, Madras Medical College and the General Hospital, Madras, for permission to publish this report. 


\section{REFERENCES}

Agnos, J. W., and Starkey, G. W. B. (1958). Primary leiomyosarcoma and leiomyoma of the lung. New Engl. J. Med., 258, 12.

Andrews, C. E. (1965). In Textbook of Pulmonary Diseases, ed. G. L. Baum, p. 580. Little Brown, Boston.

Brunn, H., and Goldman, A. (1940). The differentiation of benign from malignant polypoid bronchial tumors. Surg. Gynec. Obstet., 71, 703. Quoted by Agnos and Starkey.
Castleman, B. (1963). Case records of the Massachusetts: General Hospital, case 17. New Engl. J. Med., 268, 550.

Freireich, K., Bloomberg, A., and Langs, E. W. (1951). Primary bronchogenic leiomyoma. Dis. Chest, 19, 354.

Gale, G. L., and Delarue, N. C. (1967). Leiomyosarcoma of the bronchus. Dis. Chest, 52, 257.

Shaw, R. R., Paulson, D. L., Kee, J. L., and Lovett, V. F . (1961). Primary pulmonary leiomyosarcoma. J. thorac. cardiovasc. Surg., 41, 430. 